\title{
APLICAÇÕES DE NANOELETRODOS COMO SENSORES NA QUÍMICA ANALÍTICA
}

\author{
Francisco Claudece Pereira* \\ Departamento de Química, Universidade Federal do Rio Grande do Norte, CP 1524, 59072-970 Natal - RN, Brasil \\ Erwing Paiva Bergamo \\ Departamento de Química, Universidade Federal do Maranhão, 65085-580 São Luís - MA, Brasil \\ Maria Valnice Boldrin Zanoni \\ Departamento de Química Analítica, Instituto de Química, Universidade Estadual Paulista, \\ CP 355, 14801-970 Araraquara - SP, Brasil \\ Ligia Maria Moretto e Paolo Ugo \\ Departamento de Física e Quimica, Universidade de Veneza, Santa Marta, 2137, 30123, Veneza, Itália
}

Recebido em 11/8/05; aceito em 23/9/05; publicado na web em 5/5/06

\begin{abstract}
APPLICATIONS OF NANOELECTRODES AS SENSORS IN ANALYTICAL CHEMISTRY. Nanomaterials make up an emerging area in Chemistry and in the science of materials. This area constitutes the development of methods for synthesizing nanoscopic particles of a given material used for scientific investigation. Nanomaterials have a wide range of commercial possibilities and technological applications, including their use in analytical chemistry, as well as in electronics, optics, engineering, medicine, devices for liberation of drugs, bioencapsulation, among others. This paper presents a summary about nanoelectrodes, devices built from nanoparticles, which show great potential as electrochemical tools in many different types of analysis. The purpose of this paper is to review the construction methodologies of nanoelectrodes, and to point out their successful applicability in the various fields of immune assays and other analytical procedures with quantitative purposes.
\end{abstract}

Keywords: electroanalysis; nanoelectrode; polycarbonate membrane.

\section{NANOTECNOLOGIA - INTRODUÇÃO}

A compreensão dos fenômenos que ocorrem em escala nanométrica incorpora-se no campo do conhecimento da física, química, biologia moderna, medicina, eletrônica, dentre outros, constituindo um campo de fronteira interdisciplinar, denominado nanociência e nanotecnologia e tem sido explorado há algum tempo na química ${ }^{1,2}$.

A nanotecnologia surge como conseqüência prática de eventos científicos desenvolvidos há longas datas e permitiu que os pesquisadores vislumbrassem a matéria em seu nível fundamental, derrubando conceitos obsoletos e lançando as pilastras para um mundo anteriormente inimaginável. Com o advento dos microscópios de varredura por tunelamento, em 1981, os objetos puderam ser ampliados em mais de 10 milhões de vezes, possibilitando a manipulação de moléculas e átomos individualmente. Com o emprego do microscópio de força atômica, bem como das técnicas de ressonância magnética nuclear e de raios-X, foi possível acessar o mundo dos átomos e "enxergar" seu nível organizacional que dá suporte a todo o estudo molecular anteriormente conhecido. Assim, grandes avanços nesta área têm materializado a criação de estruturas a partir de moléculas individuais pela sobreposição de átomo sobre átomo, mudando as características primárias de um material e conferindo-lhe novas formas e propriedades ${ }^{2,3}$.

O campo da nanociência e nanotecnologia compreende dimensões na ordem de 1 a $100 \mathrm{~nm}$ o que possibilita entender, controlar e explorar a matéria em seu momento de origem contribuindo, desta forma, para intervir no processo original e decidir em que etapa de crescimento se presta uma dada estrutura ou sistema em desenvolvimento em função de suas propriedades físicas e químicas. Explorar estas propriedades pode assegurar a criação de dispositi-

*e-mail: claudece@ufrnet.br vos a nível atômico, molecular e supramolecular, o que constitui requisito essencial para as linhas de produção de qualquer área de interesse. Portanto, a nanociência toma como ponto de partida as propriedades atômicas e moleculares, governadas pelas leis insólitas da mecânica quântica para e, a partir destas, conceber e construir sistemas com propriedades ou desempenhos desejáveis ${ }^{3,4}$.

Atualmente, o mundo se torna ainda menor graças a esta ciência que constrói dispositivos no paradigma molecular revolucionando indústrias tradicionais, tais como espaço aéreo, automotivo, ferramentas, eletrônica, dispositivos médicos, motores elétricos, transistores, microchips, dentre outros. Manipulando átomos e moléculas individualmente, será possível melhorar um dado material, modificando suas propriedades, tais como condutividade, ópticas, magnéticas e termais ${ }^{5}$.

Dentro desta óptica, a nanociência abre possibilidade para o desenvolvimento de sensores com dimensões adequadas para medidas intracelulares. A possibilidade de uso de ferramentas capazes de monitorar processos biomoleculares dentro de uma única célula fornece um caminho no sentido de obter informações para compreensão e entendimento da função celular. Nas últimas duas décadas, a biotecnologia e o campo médico têm alcançado notáveis avanços no desenvolvimento de novas tecnologias e aberto novos horizontes no sentido de identificar e quantificar biomoléculas, além do diagnóstico de doenças em níveis antes inalcançáveis. Neste sentido, o desenvolvimento e a utilização de nanoestruturas como ferramentas no entendimento de processos biomimétricos tem ganhado notoriedade junto à comunidade cientifica nas últimas décadas ${ }^{6-9}$.

\section{ARRANJO DE NANOELETRODOS}

O emprego de micro e nanomateriais na eletroquímica remonta de longa data. A utilização de eletrodos de discos com dimen- 
sões microscópicas na ordem de $100 \mathrm{~nm}$ a $10 \mu \mathrm{m}$ constitui a mais importante fronteira na eletroquímica moderna. Estes micro e nanodispositivos permitem investigação de processos eletroquímicos em sistemas anteriormente não possíveis, quando de seu estudo utilizando os macro eletrodos. Exemplos de oportunidades únicas, fornecidas por estas micro e nanoestruturas, incluem a possibilidade de estudos eletroquímicos em meio que apresenta alta resistividade, como os solventes orgânicos, soluções com baixos teores de eletrólitos de suporte ou na sua completa ausência, além de permitirem investigação de processos cinéticos que ocorrem em dimensões ultra-microscópicas ${ }^{10}$.

Os nanoeletrodos (NEs) são resultados de considerável interesse teórico e prático devido as suas vantagens particulares, nas quais se destacam o melhoramento no limite de detecção e as formas distintas de difusão de espécies em uma superfície eletródica ${ }^{10,11}$. Além de apresentarem a possibilidade de operar com diminutas matrizes, também oferecem habilidade nas medidas de velocidade de transferência heterogênea de carga muito elevada ${ }^{12}$. A diminuição da superfície eletródica, da escala milimétrica tradicional à micrométrica ou nanométrica, determina algumas características importantes, tais como a redução drástica da queda ôhmica, graças à pequena corrente de eletrólise que flui na célula eletroquímica e um ganho no aumento da velocidade no transporte de massa. Desta forma, obtém-se em tempos muito breves, respostas sobre o perfil da concentração de uma dada espécie em uma solução problema ${ }^{10}$.

Arranjos de NEs são constituídos de um conjunto não ordenado de eletrodos miniaturizados resultantes da incorporação de nanofilamentos de ouro em uma matriz polimérica, alcançando as vantagens dos eletrodos com dimensões compreendidas entre 10 a $100 \mathrm{~nm}$. Esta propriedade possibilita melhor discriminação entre a corrente capacitiva da dupla camada elétrica e a faradaica, uma vez que a corrente analítica sempre apresenta proporcionalidade entre a área ativa de um eletrodo, enquanto a corrente residual se manifesta em relação à área geométrica de um dado substrato eletródico. Esta característica, intrínseca deste tipo de dispositivo, permite um ganho na sensibilidade devido à amplificação do sinal monitorado, para qualquer espécie redox e pode ser observado em discretos valores de concentração, devido à minimização da relação sinal-ruído ${ }^{10-12}$.

Para um macro eletrodo, com mesma área geométrica de um $\mathrm{NE}$, as expressões de corrente são proporcionais às suas respectivas áreas. A relação sinal-ruído em um NE será igual à mesma relação em um eletrodo convencional de mesma área, dividida pela área eletródica fracionária, que representa o somatório das nanofibras distribuídas em sua área geométrica. Este fato é responsável pela obtenção de limites de detecção na ordem de ultra-traços no estudo de um dado sistema, em relação ao mesmo sistema estudado com eletrodos convencionais. Esta relação fornece uma corrente capacitiva significativamente inferior em um NE em correspondência a um eletrodo convencional. O melhoramento, teoricamente esperado no limite de detecção, pode ser calculado dividindo-se as correntes capacitivas de ambos sistemas. O quociente desta razão mostra que é possível alcançar valores de concentração na ordem de três vezes inferiores em relação aos sistemas convencionais ${ }^{10-13}$.

\section{PREPARAÇÃO DE ARRANJOS DE NANOELETRODOS}

\section{Síntese "template"}

O método "template", comumente usado para obtenção de nanopartículas, consiste na síntese química ou eletroquímica de estruturas de um material desejado diretamente nos poros de uma membrana de ultra-filtração ("template") ${ }^{10}$. Estas membranas são confeccionadas a partir de polímeros com alta densidade, tais como policarbonato, poliéster, dentre outros. Estas matrizes são submetidas a um bombardeio de raios de alta energia para geração de seus cilindros, conforme mostra o Esquema 1. Uma larga variedade de membranas plásticas "track-etched" pode ser encontrada comercialmente.

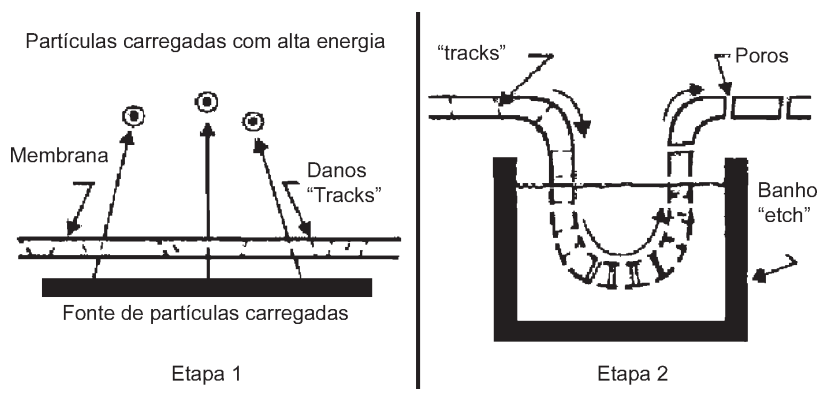

Esquema 1. Esquema de preparação "track-etch" das membranas matrizes. Adaptado da ref. 13

Em uma fase inicial (Etapa 1) a membrana sofre um bombardeio de raios colimados de partículas altamente carregadas de energia em um reator nuclear. Este processo favorece a criação de percursos com defeitos perpendiculares à superfície do polímero com um desvio de aproximadamente $30^{\circ}$. Posteriormente, esta matriz previamente bombardeada sofre ação de uma solução alcalina para formar os cilindros em correspondência aos traços obtidos com o processo anterior, (Etapa 2). O método é baseado em estudos pioneiros da década de 60 onde alguns pesquisadores ${ }^{14,15}$ relatam que os danos "track", produzidos em uma superfície de mica através da alta colisão de partículas carregadas, poderiam produzir poros com diâmetros dependentes do tempo de exposição ao processo. Este mesmo procedimento para obtenção de defeitos "etching" foi empregado em outros materiais, como minerais e plásticos ${ }^{16}$. Os resultados obtidos mostraram que é possível obter poros perfeitamente cilíndricos, aleatoriamente distribuídos e altamente dispersos em uma superfície. As dimensões dos canais obtidos podem chegar de décimos de $\mu \mathrm{m}$ a $10 \mathrm{~nm}$, dependendo dos diâmetros dos poros e de sua distribuição na matriz empregada ${ }^{16}$.

Um trabalho pioneiro nesta área é atribuído a Possin ${ }^{17}$, que empregou o processo descrito com a finalidade de obtenção de porosidade em uma superfície de mica e, em seguida, seu emprego na construção de nanomateriais. A utilização deste procedimento permitiu a eletrodeposição de metais nos poros de uma membrana, obtendo arames com diâmetros na ordem de $40 \mathrm{~nm}$. Posteriormente, esta técnica foi aprimorada e possibilitou o fabrico de fios na ordem de $8 \mathrm{~nm}^{18}$.

Dentre os métodos aqui relatados na confecção de NEs, destacam-se aqueles baseados na utilização de membranas de ultra-filtração, caracterizadas por apresentarem nanoporos cilíndricos de diâmetro uniforme, a serem usadas como hospedeiras para infiltração e preenchimento de seus canais ${ }^{10,19,20}$. Estas estruturas de policarbonato ou poliéster permitem a construção de um conjunto de eletrodos na forma de disco de ouro com um diâmetro mínimo de $10 \mathrm{~nm}$.

Estas membranas são caracterizadas por apresentarem diâmetro médio de $47 \mathrm{~mm}$ e $6 \mu \mathrm{m}$ de espessura, com densidade média de $6,0 \times 10^{8}$ poros por $\mathrm{cm}^{2}{ }^{10}$, conforme detalhes mostrados no Esquema 2. Membranas com diâmetros de poros na faixa de $10 \mathrm{~nm}$ a $0,4 \mu \mathrm{m}$ são facilmente encontradas comercialmente. Estas matrizes poliméricas são facilmente dissolvidas em muitos solventes orgânicos apresentando alta transparência na região espectral do visível e, devido a esta propriedade, facilitam a investigação espectrofotométrica de nanopartículas agregadas em seus poros. 
As superfícies destas membranas são revestidas com um extrato de polivinilpirrolidona, PVP, que fornece um caráter parcialmente hidrofílico à superfície ${ }^{10}$.

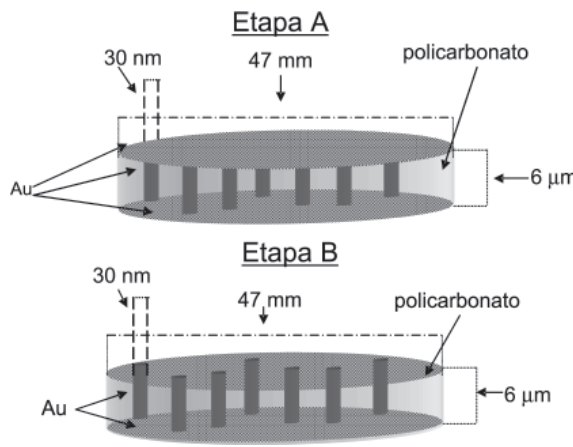

Esquema 2. Representação esquemática de membrana compósito dourada utilizada para fabricação de um NE. Adaptada da ref. 13

A técnica geralmente utilizada para deposição das fibras de ouro, ou qualquer outro metal de interesse, no interior dos poros destas matrizes hospedeiras tem sido bastante documentada na literatura ${ }^{10,18,20,21}$. O processo fundamenta-se em uma deposição não eletroquímica do metal sobre um material não condutor, como é o caso das referidas membranas. Esta técnica de deposição química consiste na ativação de uma face da matriz, de modo a favorecer cineticamente a redução da espécie metálica na interface polímerosolução em relação ao material existente no meio reacional. O resultado final deste procedimento é a obtenção de membrana preenchida de metal em seus poros e recoberta por dois extratos, nas faces superior e inferior, com medidas com cerca de $500 \mathrm{~nm}$.

A etapa inicial consiste na ativação de sua superfície em solução de estanho II. Posteriormente, a membrana ativada é submetida à reação com solução de nitrato de prata para assegurar a reação redox em sua superfície, elevando o estado de oxidação do estanho para IV e reduzindo o íon prata a prata elementar. Em seguida, o polímero revertido com Ag sofre ação do íon ouro deslocando, galvanicamente, a prata e reduzindo-se a ouro metálico diretamente na superfície da matriz $^{10}$. O produto deste processo, bem como a comparação com a membrana original pode ser visualizado na Figura 1.

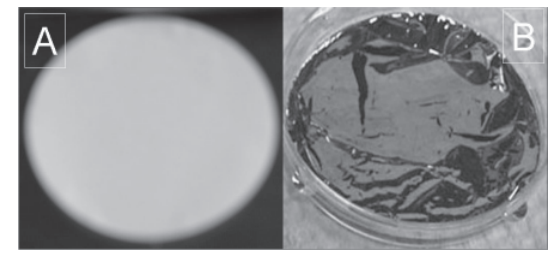

Figura 1. A: Foto de uma membrana virgem de policarbonato com poros com diâmetro de $30 \mathrm{~nm}$. B: Idêntica membrana após aplicação de processo de deposição de ouro $^{13}$

A realização do processo de deposição de ouro nos poros e na superfície de uma membrana matriz mantém inalteradas suas características originais, diferindo somente no ganho de peso (deposição de ouro). O Esquema 2 mostra as etapas preliminares para a construção de um NE.

Na etapa A, está representado o processo final de deposição do metal nos poros e na superfície da matriz. Na etapa B, a face superior do extrato superficial de ouro é removida, de modo que os nanoelementos possam emergir na forma de discos cilíndricos e isolados. Todavia, o extrato inferior do metal deve ser mantido para efetuar o contato elétrico entre estes elementos e o conjunto eletródico.
O processo final para obtenção de um NE consiste em diversos procedimentos, conforme indicado a seguir: o extrato superficial superior de ouro é removido simplesmente com a utilização de uma fita scotch do tipo "Magic" (produzida pela $3 \mathrm{M}^{\circledR}$ ); um pedaço de fita de cobre condutor $(6 \times 40 \mathrm{~mm})$ é fixado sobre um pequeno quadrado de alumínio adesivo (não condutor) de $1 \mathrm{~cm}$ de lado; na parte central do quadrado de alumínio, previamente aderido à fita de cobre é fixado um pedaço da membrana dourada de aproximadamente $5 \times 5 \mathrm{~mm}$ com a sua face inferior dourada e original, que funcionará como contato elétrico e garantirá o fluxo eletrônico proveniente do potenciostato aos nanodiscos e vice-versa e, finalmente, é aplicada a este conjunto, uma fita com a finalidade de isolar e delimitar a área de trabalho. Esta área é obtida através da realização de um furo na fita executado no final de todo o processo ${ }^{10}$. A ilustração, bem como o arranjo final referente à montagem do eletrodo é mostrada em detalhes por Menon ${ }^{10}$.

\section{CARACTERÍSTICAS MORFOLÓGICAS DOS NANOELETRODOS EM MEMBRANAS POLIMÉRICAS}

Diversos autores têm utilizado a microscopia eletrônica de varredura, MEV, como ferramenta analítica para estabelecer parâmetros superficiais destes materiais ${ }^{10,22-26}$. A aplicação desta técnica é comumente empregada para avaliar superfícies de amostras sólidas com a finalidade de obter informações morfológicas e topográficas dos nanoelementos depositados após procedimento de redução do íon ouro no interior dos canais nas membranas, bem como em suas superfícies. Para a realização deste tipo de estudo é prática usual a remoção prévia dos extratos externos do metal depositado em ambas faces da matriz, de modo que os elementos possam ser visualizados. As imagens MEVs obtidas deste procedimento podem ser conferidas na Figura 2.

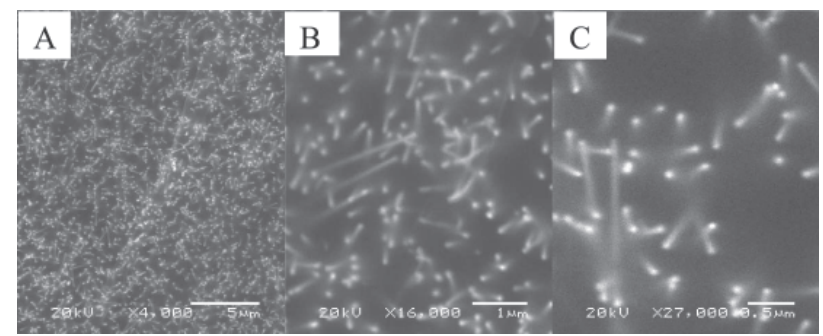

Figura 2. Imagens $M E V$ de membrana de policarbonato com porosidade de $30 \mathrm{~nm}$ dourada pelo processo de deposição química de ouro. As micrografias apresentam magnitudes de $4.000 x \mathrm{em}(A) ; 16.000 x \mathrm{em}(B)$ e $27.000 x \mathrm{em}(C)$ com uma energia de $20 \mathrm{keV}^{13}$

A análise da Figura 2A mostra diversos pontos destacados na imagem, que representam o preenchimento dos nanocanais da matriz polimérica com ouro elementar. Através das imagens é possível constatar que este tipo de matriz apresenta uma alta porosidade aleatoriamente distribuída, devido ao próprio processo "track-etch" de obtenção dos poros. Melhor aproximação desta imagem é mostrada nas Figuras 2B e C que confirmam este tipo de diagnóstico. Uma observação mais criteriosa permite concluir que, com o preenchimento dos canais da matriz, fica evidente que a obtenção dos poros ocorre, majoritariamente, quase perpendicularmente (trajetória oblíqua) ao plano da membrana. Todavia, a constatação de alguns "cometas" no polímero, possibilita deduzir que alguns percursos se apresentam de forma transversal, com um ângulo de aproximadamente $30^{\circ}$, confirmando que este processo é dependente da etapa de fabrico dos nanocilindros no polímero. Com este tipo de estudo também é possível calcular a respectiva porosidade de dada membrana. 
Diversos estudos descritos na literatura ${ }^{22,27-30}$, têm mostrado a viabilidade de se proceder à dissolução da matriz empregada para executar uma investigação mais aprofundada sobre a estrutura destes arames formados dentro dos canais da membrana. O perfil destes fios, gerados durante o processo de crescimento destas estruturas, pode apresentar características como aquelas mostradas na Figura 3.

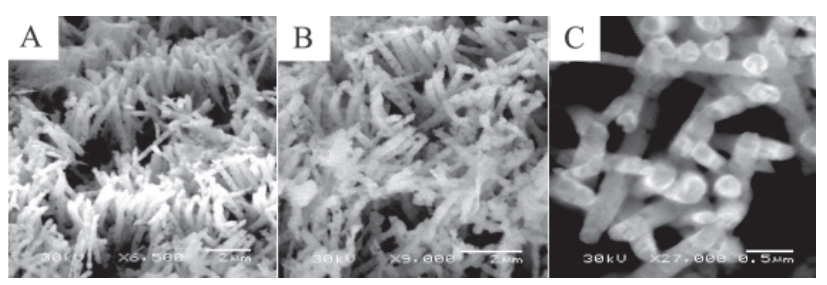

Figura 3. Imagens MEV de membrana de policarbonato dourada através de processo de deposição química de ouro, seguido de sua dissolução em diclorometano. As micrografias apresentam uma magnitude de $6.500 x \mathrm{em}$ (A); $9.000 x$ em (B) e 27.000x em (C) com uma energia de $30 \mathrm{keV}^{13}$

Na Figura 3A é possível observar um aglomerado de fios livres e randomicamente distribuídos na superfície de apoio após dissolução da matriz original. As amplificações destas imagens são mostradas nas Figuras 3B e 3C, as quais apresentam melhor resolução, permitindo uma visualização mais detalhada dos nanofios de ouro. As características espaciais destes elementos representam uma rede de filamentos que crescem íntegros em toda a espessura da matriz. Estes nanoarames são os responsáveis pelo contacto e condução eletrônica entre uma dada espécie em solução e o potenciostato, uma vez que as referidas membranas se comportam como isolantes. Na Figura 3C, a amplificação permite concluir que estas estruturas são cilindros, compactos e sólidos, em toda a sua extensão.

\section{CARACTERÍSTICAS ELETROQUÍMICAS DOS NANOELETRODOS EM MEMBRANAS POLIMÉRICAS}

O comportamento voltamétrico observado sobre nanoestruturas tem sido bem documentado na literatura ${ }^{10,11,20,22,25,27,31,32}$. Via de regra, estes dispositivos apresentam uma baixa corrente capacitiva e costumam operar na escala de nanoamper. A Figura 4 mostra voltamogramas cíclicos obtidos em solução de $1,00 \times 10^{-3} \mathrm{~mol} \mathrm{~L}^{-1}$ de $\mathrm{NaNO}_{3}$ para um NE (Figura 4A) sintetizado de maneira descrita previamente e para um macro eletrodo de ouro (Figura 4B).

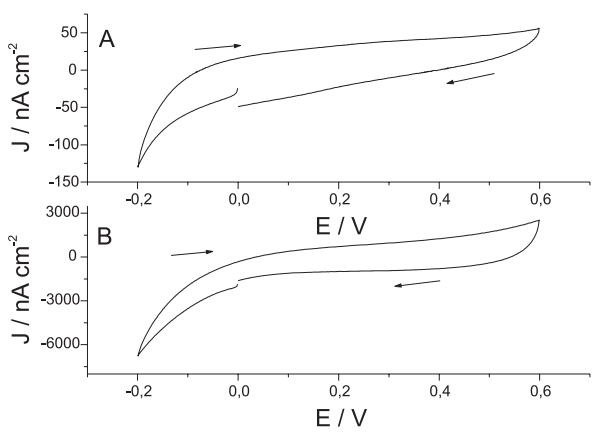

Figura 4. Voltamogramas cíclicos obtidos para um NE (A) e um eletrodo de ouro convencional (B), em solução $1,0 \times 10^{-3} \mathrm{~mol} \mathrm{~L}^{-1}$ de $\mathrm{NaNO}_{3}, \mathrm{v}=20 \mathrm{mV} \mathrm{s}^{-113}$

O claro contraste entre as correntes da dupla camada elétrica, para ambos sistemas eletródicos, permite observar uma forte atenuação da corrente capacitiva observada sobre nanoestruturas. As medidas de densidades de corrente podem apontar valores próximos da razão de 40-50 vezes menores em um NE, quando comparado com eletrodos convencionais. Esta propriedade permite a obtenção de resultados vantajosos no estudo eletroquímico de sistemas redox, possibilitando alcançar discretos limites de detecção em relação a um mesmo estudo conduzido sobre macro superfícies.

A Figura 5 ilustra o ganho na resolução das respectivas curvas voltamétricas registradas para um sistema redox padrão (ferroceno $1 \times 10^{-5} \mathrm{~mol} \mathrm{~L}^{-1}$ em nitrato de sódio) sobre um arranjo de NE e um eletrodo de ouro convencional. Os resultados indicam um nítido melhoramento na forma da onda voltamétrica sobre um NE (Figura 5A), cuja amplificação do sinal redox mostra as vantagens da utilização destes dispositivos como ferramenta na eletroanálise. A resposta obtida, para as mesmas condições experimentais, empregando-se um eletrodo de ouro convencional é mostrada na Figura 5B.

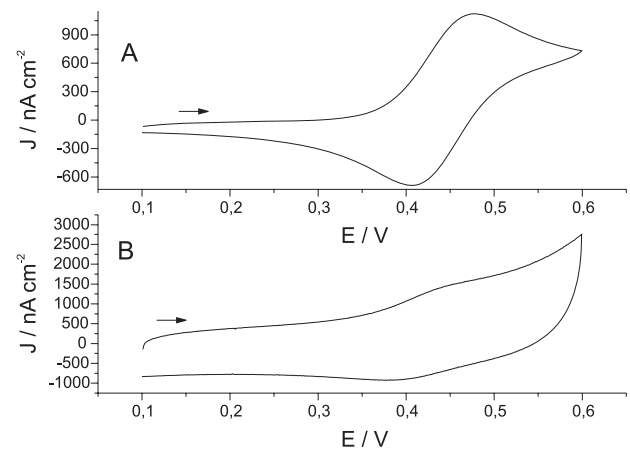

Figura 5. Voltamogramas cíclicos obtidos para oxidação de $1,00 \times 10^{-5} \mathrm{~mol} \mathrm{~L}^{-1}$ de ferroceno em $1,00 \times 10^{-3} \mathrm{~mol} \mathrm{~L}^{-1}$ de nitrato de sódio sobre um $\mathrm{NE}(\mathrm{A})$, e com um eletrodo de ouro convencional (B). v $=20 \mathrm{mV} \mathrm{s}^{-1} 13$

Como discutido previamente, isto ocorre porque a razão entre corrente faradaica e corrente capacitiva nos NEs e nos eletrodos convencionais está relacionada com a área geométrica por: $\left(\mathrm{I}_{\mathrm{F}} / \mathrm{I}_{\mathrm{C}}\right)_{\mathrm{NE}}=$ $\left(\mathrm{I}_{\mathrm{F}} / \mathrm{I}_{\mathrm{C}}\right)_{\mathrm{Conv}} \times \mathrm{A}_{\text {geom }} / \mathrm{A}_{\mathrm{at}}$; onde $\mathrm{I}_{\mathrm{F}}$ corrente faradaica, $\mathrm{I}_{\mathrm{C}}$ corrente capacitiva, $\mathrm{A}_{\text {geom }}$ área geométrica total e $\mathrm{A}_{\text {at }}$ área ativa, segundo um fator de proporcionalidade dado pelo inverso da fração das áreas dos eletrodos $\left(f=\mathrm{A}_{\mathrm{at}} / \mathrm{A}_{\text {geom }}\right)$. Essa razão é menor nos NEs que aquela considerada para um eletrodo convencional de mesma área geométrica. Todos os cálculos matemáticos empregados no tratamento das leituras de corrente e potencial, bem como as distintas formas de difusão de espécies redox em uma interface solução/NE, são discutidos em detalhes na literatura ${ }^{33}$. Porém, de modo geral é possível concluir que os valores de $f$ nos NEs estão entre $10^{-3}$ a $10^{-2}$, expressando o ganho na razão do sinal em relação à corrente capacitiva e, por conseguinte, expressa melhora no limite de detecção de, pelo menos, duas a três ordens de grandeza em relação aos eletrodos convencionais.

A capacidade dos NEs em exibir voltamogramas cíclicos melhores definidos mesmo para traços de espécies redox tem conseqüências interessantes, não apenas para sistemas bem comportados, mas também para substâncias que apresentam o indesejável fenômeno de adsorção. De acordo com a literatura ${ }^{34}$, este fenômeno é dependente da concentração da espécie eletroativa. Sistemas que permitem monitoramento em pequenos níveis de concentração de analitos, tais como os NEs, podem apresentar a vantagem de minimizar estes efeitos, uma vez que o processo redox pode ser executado em baixíssimos teores do substrato analisado, com conseqüente diminuição no envenenamento da superfície do eletrodo ${ }^{31}$.

OUTROS TIPOS DE CONSTRUÇÃO DE NANOELETRODOS

Embora a construção e o emprego de nanoeletrodos, montados 
em matrizes poliméricas, tenham se consolidado como uma nova vertente na eletroanálise, outras classes de manufatura e "design" de nanossensores também têm sido relatadas na literatura, o que vem a corroborar esta nova tendência entre os eletroanalistas. Os trabalhos mais relevantes são descritos a seguir.

Dispositivos eletroquímicos com escala entre 4 a $25 \mathrm{~nm}$ foram construídos por Bezryadin ${ }^{35}$. Neste trabalho é relatado o sucesso na utilização de nanopartículas coloidais de Pd na construção de um eletrodo planar, suportado em camadas de filmes de silício. Sobre esta plataforma, comumente é depositado $\mathrm{SiN}$ dotado de um canal onde podem ser fixados dois eletrodos de Pt interligados a um circuito operacional, para geração de um campo elétrico capaz de produzir um gradiente de carga entre estes terminais. Após o fechamento do circuito eletrônico, um fluxo de uma suspensão de Pd é conduzido através do canal onde ocorre atração eletrostática seguida da redução da espécie metálica diretamente na superfície da Pt, aumentando, desta forma, a massa de metal sobre um dos eletrodos e diminuindo a espessura do canal. Nesta etapa, observa-se que as dimensões do eletrodo de Pt podem ser controladas através da programação da carga que flui pelo dispositivo eletrônico. Portanto, é possível a obtenção de eletrodos espaçados com distâncias dependentes do tempo de deposição do experimento.

Uma nova técnica de fabricação de arranjo de nanoeletrodos é relatada por Jeouhg ${ }^{36}$, empregando os polímeros poliestireno e polimetilmetacrilato como matrizes dispersas sobre filme constituído de ouro e silício. O dispositivo foi caracterizado através de técnicas voltamétricas utilizando a espécie padrão ferroceno, e os resultados mostraram que o processo de transporte de massa para a superfície do eletrodo é governado por difusão da espécie quando se emprega velocidades de varredura $<250 \mathrm{mV} \mathrm{s}^{-1}$. Porém, empregando altos valores de velocidade de varredura, observa-se um sinal com característica sigmoidal, comprovando que os nanodiscos estão operando em regime de total independência.

Várias membranas de policarbonato com diferentes diâmetros de poros, de 10, 30, 50, 80 e $200 \mathrm{~nm}$, também foram utilizadas por Schonenberg ${ }^{30}$ como matrizes para deposição e crescimento galvanostático de nanoarames de níquel, cobalto, cobre e ouro, além de estruturas de polipirrol. Os procedimentos empregados para a deposição de cada metal nos poros da membrana isolante consistem em metalizar uma das faces da matriz de modo que se possa assegurar o contato elétrico com o potenciostato. O emprego de um valor de potencial fixo permite a migração das espécies metálicas da solução ao eletrodo, passando pelos canais da matriz. Um rigoroso controle das etapas experimentais permite a obtenção de nanocilindros com geometria diferenciada para cada tipo de eletrodo. As medidas de comprimento, bem como o diâmetro de cada elemento, foram estimadas após a dissolução da matriz em diclorometano e os resultados mostraram que as estruturas se desenvolveram em conformidade com os canais da matriz polimérica, seguido de um crescimento superficial e formação de estruturas com aspecto de cogumelos, quando a deposição é conduzida em tempos longos.

Uma nova classe de nanoeletrodos aplicados como sensores amperométricos foi relatada por Wang ${ }^{37}$. Estes novos dispositivos foram obtidos utilizando-se uma lâmina de quartzo como plataforma de apoio para deposição de uma camada de silício, seguido da geração de um filme de carbono, obtido pela pirólise do polímero poliacrilonitrilo diretamente na superfície do "slide", sendo o contato elétrico estabelecido com a utilização de um fio de cobre e o emprego de cola de prata. O dispositivo foi devidamente caracterizado através de técnicas voltamétricas utilizando o padrão ferricianeto de potássio e as respostas obtidas apresentaram valores de capacitância dependentes da largura das bandas para cada filme de carbono. As curvas mostraram comportamento sigmoidal, característico de ultra micro superfícies e difusão não linear para a espécie redox empregada. Os eletrodos mostraram-se eficazes para o monitoramento de espécies em meio de alta resistividade, como no caso dos solventes orgânicos, onde foi possível investigar o comportamento redox do ferroceno em acetonitrila.

Em outra comunicação, Wang ${ }^{38}$ descreveu a construção de um sensor enzimático, denominado de nanofaixa. Este trabalho é um desdobramento do anterior ${ }^{37}$, onde uma lâmina de quartzo $(25 \times 25$ $\mathrm{mm}$ ) foi utilizada como suporte para deposição de filmes de carbono com espessuras compreendidas entre 35 a $50 \mathrm{~nm}$. Sobre a camada condutora de carbono, promoveu-se a imobilização do polímero poli-o-fenildiamina e da enzima glicose oxidase, seguido dos procedimentos convencionais de tratamento de materiais biológicos. O mesmo tipo de eletrodo serviu para a construção de outros dispositivos amperométricos baseados na imobilização de tirosinase e álcool oxidase, tratados de formas similares aos procedimentos descritos anteriormente.

Um novo "design" de nanoeletrodos do tipo agulha foi apresentado por Katemann ${ }^{39}$. Esta modalidade de sensor é construída a partir da inserção de um fio de platina dentro de um capilar de vidro de borossilicato e o conjunto submetido a um tratamento térmico à base de "laser", provocando uma dilatação dos corpos e a respectiva selagem da platina com o material isolador. Em um dado estágio do aquecimento, os materiais são esticados por um dispositivo, de modo que se projetem ao longo de seus eixos, resultando em um conjunto longo e alcançando as magnitudes desejadas. Os estudos desenvolvidos, empregando técnicas de MEV, realizados na ponta destes dispositivos mostraram que o material condutor pode apresentar dimensões tão pequenas quanto $6 \mathrm{~nm}$. Outros diâmetros para a platina podem ser obtidos empregando-se um rigoroso controle da temperatura de aquecimento, bem como da etapa de alongamento dos materiais em estágio de fusão. A caracterização deste tipo de dispositivo foi realizada tomando uma solução do complexo hexaminrutênio (III) na presença de cloreto de potássio e as curvas voltamétricas observadas mostraram respostas sigmoidais e de correntes de difusão limitada, características de registros gráficos de corrente contra potencial obtidas sobre superfícies miniaturizadas. Outras manufaturas deste tipo de eletrodos também foram relatadas por Zoski ${ }^{40}$.

\section{APLICAÇÕES DE NANOELETRODOS COMO SENSORES}

A síntese e aplicação de nanoestruturas na área dos biossensores têm ganhado notoriedade junto à comunidade científica, devido a sua grande versatilidade e amplo espectro de utilização no campo dos ensaios analíticos. Seu emprego tem demonstrado grande sucesso, uma vez que a miniaturização dos eletrodos potencializa o monitoramento da interação de receptores anexados em arranjos de nanoestruturas, com alguns materiais biológicos, tais como proteínas, antígenos, enzimas e anticorpos.

Dentro deste contexto, Bauer ${ }^{41}$ tem mostrado interessantes interações de receptores quando ancorados em arranjos de nanomateriais, possibilitando o destaque da eficiência de ressonância do material condutor, a qual foi vantajosamente explorada para investigar as distintas formas de interação destes biomateriais.

Outra potencialidade das nanoestruturas é seu emprego para investigação sobre o comportamento redox de certas proteínas. Em sistemas convencionais, a adsorção direta de enzimas na superfície metálica de macroeletrodos freqüentemente promove sua desnaturação e, por conseguinte, a perda de sua bioatividade. Ao contrário, quando estes materiais biológicos são adsorvidos sobre nanopartículas, sua atividade permanece inalterada ${ }^{42}$. Nesse trabalho, o autor descreve a utilização de partículas coloidais de ouro 
utilizadas como matriz para adsorver enzimas sem prejuízo em seu rendimento. Adicionalmente, outros autores ${ }^{19}$ têm mostrado que o citocromo $\mathrm{C}$ pode apresentar comportamento ciclo voltamétrico reversível quando depositado em um substrato revestido com partículas de ouro de $12 \mathrm{~nm}$ de diâmetro. A comparação de seus resultados, quando são utilizadas largas superfícies de ouro, mostra que a resposta voltamétrica do analito se apresenta com ampla dificuldade de transferência de carga e os voltamogramas são caracterizados com resposta quase reversível ou irreversivel, indicando a desnaturação da proteína.

Ward ${ }^{43}$ tem mostrado o desenvolvimento de um biossensor com capacidade de explorar as propriedades acústicas das ondas e, portanto, podendo ser empregado como ferramenta em imunoensaios. Nesse procedimento, um anticorpo modificado com nanopartículas de um sol mostra habilidade para se ligar à superfície de um eletrodo, utilizando um agente complexante para melhorar sua aderência. $\mathrm{O}$ alto teor de massa da ligação das partículas agregadas afeta a frequiência de vibração de um cristal de quartzo, o qual foi empregado para a detecção direta da espécie.

Arranjos de nanoeletrodos, constituídos de fibras de carbono utilizados como recheio nos cilindros de um substrato de silício, também têm sido descritos ${ }^{21}$. Nesse trabalho é apresentado o desenvolvimento de um biossensor para glicose, construído através da imobilização da enzima glicose oxidase diretamente imobilizada na superfície dos nanocilindros via reação de formação de uma amida, utilizando os próprios grupos carboxilatos existentes no material eletródico. O sensor permitiu a quantificação amperométrica de glicose na presença de ácido úrico, acetaminofen e ácido ascórbico, sem interferência destes materiais comumente encontrados em ensaios biológicos.

Em trabalho recente, Jianrong ${ }^{44}$ mostrou novas aplicações tecnológicas na área de biosensores, o que comprova a consolidação desses dispositivos como ferramenta na pesquisa. Relata o sucesso obtido na imobilização de cisteamina em partículas coloidais de ouro de $16 \mathrm{~nm}$, destacando sua capacidade de detecção para ácidos nucléicos. O dispositivo possibilitou a quantificação eletroquímica direta de DNA em níveis de concentração tão baixos quanto $5 \times 10^{-10}$ mol L ${ }^{-1}$. O mesmo estudo também mostra a eficiência de um outro biossensor construído com ouro coloidal para ensaios em sistemas enzimáticos com comprovada habilidade para monitoramento de peróxido de hidrogênio, glicose, xantina e hipoxantina, apresentando limites de detecção na ordem de $0,4 \mu \mathrm{mol} \mathrm{L} \mathrm{L}^{-1}$.

Uma metodologia eletroquímica com reconhecimento molecular foi apresentada por Finot ${ }^{45}$, que descreveu a utilização de um arranjo de estruturas integradas com dimensões de $100 \mathrm{~nm}$ de largura e distância entre os elementos de $200 \mathrm{~nm}$ construídos com cilindros de ouro elementar. O dispositivo foi modificado com DNA para investigar as propriedades de hibridização e transferência de carga do substrato na superfície do eletrodo miniaturizado. A comparação dos resultados voltametricos obtidos mostrou valores de corrente muito mais destacados em relação aos macro e microeletrodos utilizados, em correspondência à relação sinal faradaico e corrente capacitiva.

Ballarin e colaboradores ${ }^{27}$ mostraram a viabilidade da construção de um dispositivo para fins biológicos, utilizando membrana compósito de alumina, empregada como matriz para fabricação de um eletrodo com dimensões nanométricas. Este tipo de material tem proporcionado um alto grau de seletividade para espécies que apresentam pequeno diâmetro e carga elétrica melhorando, substancialmente, o fluxo do analito em direção à superfície do eletrodo. Este protótipo foi fabricado para fins de aplicação como sensor para glicose, baseado na imobilização de glicose oxidase e ferrocenocarboxilase. As correntes catalíticas observadas para oxi- dação de glicose foram vantajosamente exploradas para sua quantificação, permitindo seu monitoramento dentro dos níveis fisiológicos.

Outras possibilidades de aplicações destes dispositivos foram descritas por Ugo e colaboradores ${ }^{20}$, que têm utilizado a superfície de um NE modificada com um polímero sintético, para estimar constantes físicas de processos de transferência de carga. Um eletrodo de $30 \mathrm{~nm}$ foi obtido a partir de membrana de policarbonato e utilizado como suporte para imobilização de filmes do polímero de troca iônica poli éster sulfonado (AQ 55). Os substratos investigados foram o complexo hexaaminrutênio e hexafluorfosfato de (ferrocenilmetil)trimetilamina. Estas espécies foram incorporadas nos filmes de AQ55 através da imersão do NE modificado em suas respectivas soluções e analisadas na célula eletroquímica constituída somente de nitrato de sódio $1 \times 10^{-3} \mathrm{~mol} \mathrm{~L}^{-1}$. Os ensaios quantitativos mostraram que a utilização do nanodispositivo permite alcançar concentrações em 3 ordens de grandeza inferior quando comparado com eletrodos convencionais.

O comportamento ciclo voltamétrico de três mediadores de transferência de carga comumente empregados em biossensores foi descrito por Brunetti ${ }^{31}$. Os substratos investigados nesse trabalho foram dois derivados da fenotiazina e o metilviologen, os quais foram estudados sobre superfícies de ouro de $30 \mathrm{~nm}$ de diâmetro e macro eletrodos do mesmo metal. Todas as espécies analisadas apresentaram forte adsorção dos produtos gerados nas superfícies dos eletrodos convencionais, enquanto que este fenômeno não foi observado quando o ensaio era executado com a utilização dos NEs. $\mathrm{O}$ comportamento adsortivo para estas espécies foi atribuído às altas concentrações requeridas quando da utilização dos eletrodos macroscópicos, enquanto os NEs permitem operar em concentrações inferiores eliminando, desta forma, os indesejáveis efeitos de afinidade de superfície.

Em comunicação recente, Moretto $^{46}$ explorou as potencialidades para aplicações analíticas dos NEs no monitoramento e na detecção de espécies redox. Avaliou-se a influência da área ativa dos NEs, construídos de modo similar àqueles já relatados, mudando somente a área geométrica para cada dispositivo. Seus resultados mostraram que o processo de transferência de carga, observado para o padrão (ferrocenilmetil)trimetilamonium, apresenta comportamento similar sobre qualquer uma das áreas geométricas investigadas, diferindo somente nas leituras de corrente para cada dispositivo. A aplicação do ensaio voltamétrico foi realizada para detecção da proteína citocromo $\mathrm{C}$ e os resultados mostraram ser possível seu estudo na ausência de qualquer mediador, até mesmo em concentrações a níveis de ultra-traços, monitorando-se a transferência eletrônica no sítio ativo da molécula no par redox $\mathrm{Fe}^{\mathrm{II} / \mathrm{III}}$. Estes resultados são relevantes, uma vez que parte dos estudos envolvendo sistemas biológicos necessita do emprego de enzimas, um tipo de substância que apresenta preço elevado, dificuldade na purificação e baixa estabilidade frente a processos de desnaturação.

Novas aplicações sobre nanoestruturas, explorando as propriedades catalíticas de algumas substâncias comumente empregadas na eletroanálise são relatadas por Karyakin e colaboradores ${ }^{47}$. Nesse trabalho é descrito o desenvolvimento de estruturas do complexo azul da Prússia, geradas diretamente dentro das nanocavidades de uma matriz de cristal líquido elaborada a partir de alguns agentes tensoativos não iônicos, tais como Brij-56 e Twenn-60. Uma vez obtida a membrana, a mesma pode ser fisicamente depositada na superfície de um eletrodo de carbono vítreo seguido do preenchimento de seus canais, via ciclagem de potencial. Em seguida, os materiais de preenchimento são submetidos à ativação eletroquímica apresentando excelente ação catalítica para a redução de peróxido de hidrogênio. Os resultados obtidos deste proce- 
dimento atestam que o dispositivo mostra uma eficiência muito mais destacada quando comparada com a performance do eletrodo de carbono vítreo utilizado, porém na ausência do desenvolvimento da metodologia proposta.

A construção de um sistema de detecção amperométrica acoplada à análise em fluxo para monitoramento de glicose tem sido relatada na literatura ${ }^{48}$. Nesse trabalho, uma membrana de policarbonato foi utilizada como matriz para hospedar as nanoestruturas usadas para imobilização de glicose oxidase e ácido mercaptopropiônico, covalentemente ancorados diretamente na superfície do NE via reação com glutaraldeido ou carbodiimida. O sensor permitiu a construção de uma curva analítica para glicose entre 0,2-30 $\mathrm{mmol} \mathrm{L}^{-1}$, apresentando alta repetibilidade e estabilidade. A metodologia descrita permite o monitoramento de glicose na presença de ácido úrico e ácido ascórbico, sem prejuízo no rendimento do ensaio amperométrico.

O dispositivo anteriormente descrito por Wang ${ }^{38}$ foi aplicado para monitoramento de peróxido de hidrogênio, gerado pela degradação enzimática da glicose, através de sua imobilização na superfície do eletrodo em faixa. $\mathrm{O}$ sensor permitiu sua determinação amperométrica a um potencial fixo de $+0,75 \mathrm{~V}(\mathrm{Ag} / \mathrm{AgCl})$, através da construção de uma curva analítica linear até $1 \times 10^{-2} \mathrm{~mol} \mathrm{~L}^{-1}$. A repetibilidade e estabilidade do sinal foram investigadas e atestaram a confiabilidade do dispositivo proposto. Outros sensores foram construídos de maneira análoga e testados para imobilização de glicose oxidase, tirosinase e álcool oxidase e permitiram a obtenção de curvas de trabalho para fenol e etanol lineares em amplos intervalos de concentração. Os estudos permitiram concluir que a construção dos novos sensores possibilita a determinação destes substratos na presença de espécies potencialmente interferentes, comumente presentes nos ensaios realizados em matrizes biológicas.

\section{CONCLUSÕES}

De forma geral, a nanotecnologia e as nanoestruturas têm revolucionado os conceitos da química e da física e se firmado como uma nova e emergente área dos materiais. Assim, o emprego da escala miniaturizada tem ganhado notoriedade junto à comunidade científica, por apresentar características bem peculiares e permitido um rigoroso controle das etapas de seu desenvolvimento para aplicações especificas, tais como fotocatálise, bioencapsulamento, bioreatores, separação molecular e dispositivos eletrônicos e eletrópticos. Do ponto de vista de seu emprego como sensores na eletroquímica, estes dispositivos apresentam grande potencialidade e um largo espectro de utilização, tanto no campo dos bioensaios, como ferramenta analítica para determinação de espécies em solução.

Após esta fase inicial, onde se caminha para o domínio na construção e conhecimento do comportamento eletroquímico destes nanoeletrodos, é certo que em um futuro próximo, se tenha acesso à aplicação destes sensores na investigação de fenômenos biológicos a nível celular, sem necessidade de processos cirúrgicos complicados e quase sempre traumatizantes. Com os recentes avanços na área de nanotecnologia, em breve estes elementos estarão ao alcance e a serviço das pessoas, na forma de dispositivos manuais e portáteis, como instrumentos versáteis no diagnóstico e combate das mais variadas complicações.

\section{AGRADECIMENTOS}

Ao suporte financeiro da FAPESP e da CAPES para realização do estágio na Itália e para o desenvolvimento deste trabalho.

\section{REFERÊNCIAS}

1. Goho, A.; Science News 2004, 165, 87.

2. Weber, A.; Assembly 2004, 47, 54.

3. Mokhoff, N.; Electronic Engineering Times 2003, 10, 18.

4. Wu, C.; Science News 1997, 151, 14.

5. William, S. B.; J. Nanopar. Res. 2004, 6, 285.

6. Alexander, Y.; Yuri, O.; Med. Hypot. 2004, 63, 149.

7. Tuan, V. D.; Brian, M. C.; David, L. Stokes.; Sens. Actuators, B 2001, 74, 2.

8. Lampton, C.; Divertindo-se com Nanotecnologia, Ed. Berkeley: São Paulo, 1994.

9. Chen, J.; Miao. Y.; He, N.; Wu, X.; Li, S.; Biotechnol. Adv. 2004, 22, 505.

10. Menon, V. P.; Martin, C. R.; Anal. Chem. 1995, 67, 1920.

11. Penner, R. M.; Martin, C. R.; Anal. Chem. 1987, 59, 2625.

12. Penner, R. M.; Heben, M. J. T.; Longin, L. N.; Lewis, S.; Science 1990, 250, 1118.

13. Pereira, F. C.; Tese de Doutorado, Universidade Estadual Paulista, Brasil, 2003.

14. Price, P. B.; Walker, R. M.; J. Appl. Phys. 1962, 33, 3407.

15. Fleischer, R. L.; Price, P. B.; Walker, R. M.; J. Appl. Phys. 1963, 34, 2903.

16. Fleischer, L.; Price, P. B.; Walker, R. M.; Nuclear Tracks In Solids, University of California Press: Berkeley, 1975.

17. Possin, E.; Rev. Sci. Instrum. 1970, 41, 772

18. Williams, W. D.; Giordano, N.; Rev. Sci. Instrum. 1984, 55, 410.

19. Brown, K. R.; Fox, A. P.; Natan, M. J.; J. Am. Chem. Soc. 1996, 118, 1154.

20. Ugo, P.; Moretto, L. M.; Bellomi, S.; Menon, V. P.; Martin, C. R.; Anal. Chem. 1996, 68, 4160.

21. Lin, Y.; Lu, F.; Tu, Y.; Ren, Z.; Nano Lett. 2004, 4, 191.

22. Hulteen, J. C.; Martin, C. R.; J. Mater. Chem. 1997, 7, 1075.

23. Foss, C. A. J.; Hornyak, G. L.; Stockert, J. A.; Martin, C. R.; J. Phys. Chem. 1994, 98, 2963.

24. Foss, C. A. J.; Hornyak, G. L.; Stockert, J. A.; Martin, C. R.; J. Phys. Chem. 1992, 96, 7497.

25. Hulteen, J. C.; Menon, V. P.; Martin, C. R.; J. Chem. Soc. Faraday Trans. 1996, 92, 4029.

26. Martin, C. R.; Science 1994, 266, 1961.

27. Ballarin, B.; Brumlik. C. J.; Lawson, D. R.; Liang, W.; Dyke, L. S. V.; Martin, C. R.; Anal. Chem. 1992, 64, 2647.

28. Cepak, V. M.; Martin, C. R.; Chem. Mater. 1999, 11, 1363.

29. Cepak, V. M.; Hulteen, J. C.; Che, G.; Jirage, K. B.; Lakshmi, B. B.; Fisher, E. R.; Martin, C. R.; Chem. Mater. 1997, 9, 1065.

30. Schonenberger, C.; Zande, B. M. I.; Fokkink, L. G. J.; Henny, M.; Schmid, C.; Kruger, M.; Huber, R.; Birk, H.; Staufer, U.; J. Phys. Chem. B 1997, 101, 5497.

31. Brunetti, B.; Ugo, P.; Moretto, L. M.; Martin, C. R.; J. Electroanal. Chem. 2000, 491, 166.

32. Cheng, F.; Whiteley, L. D.; Martin, C. R.; Anal. Chem. 1989, 61, 762.

33. Ugo, P.; Moretto, L. M.; Vezza, F.; Chemphyschem. 2002, 3, 917.

34. Bard, J. A.; Electrochemical Methods - Fundamentals and Applications, Wiley: New York, 1980, cap. 5.

35. Berzyadin, A.; Dekker, C.; Apll. Phys. Lett. 1997, 71, 1273.

36. Jeoung, E.; Galow, T. H.; Schotter, J.; Bal, M.; Ursache, A.; Tuominen, M. T.; Stafford, C. M.; Russell, T. P.; Rotello, V.; Langmuir 2001, 17, 6396.

37. Wang, J.; Brennsteiner, A.; Electroanalysis 1991, 3, 505.

38. Wang, J.; Naser, N.; Anal. Lett. 1993, 26, 1333.

39. Katemann, B. B.; Schuhmann, W.; Electroanalysis 2002, 14, 22.

40. Zoski, C. G.; Electroanalysis 2002, 14, 1041.

41. Bauer, G.; Pittner, F.; Schalkhammer, T.; Microchim. Acta 1999, 131, 107.

42. Crumbliss, A. L.; Perine, S. C.; Stonehuerner, J.; Tubergen, K. R.; Zhao, J. G.; Henkens, R. W.; Biotechnol. Bioeng. 1992, 40, 483.

43. Ward, M. D.; Ebersole, R. C.; US pat. 5,501,986 1996. (CA 128: PO8909938w)

44. Jianrong, C.; Yuqing, M.; Nongyue, H.; Xiaohua, W.; Sijiao, L.; Biotechnol. $A d v .2004,22,505$.

45. Finot, E.; Bourillot, E.; Prest, R. M.; Lacroute, Y.; Legay, G.; Malki, M. C.; Latruffe, N.; Siri, O.; Braunstein, P.; Dereux, A.; Ultramicroscopy 2003, 97, 441.

46. Moretto, L. M.; Pepe, N.; Ugo, P.; Talanta 2004, 62, 1055.

47. Karyakin, A. A.; Puganova, E. A.; Budashov, I. A.; Kurochkin, I. N.; Karyakina, E. E.; Levchenko, V. A.; Matveyenko, V. N.; Varfolomeyev, S. D.; Anal. Chem. 2004, 76, 474.

48. Delvaux, M.; Champagne, S. D.; Walcarius, A.; Electroanalysis 2004, 16, 190. 